\title{
A New Multi-Phase Algorithm for Stemming in Farsi Language Based on Morphology
}

\author{
Somayyeh Estahbanati, Reza Javidan, Member, IACSIT, and Mehdi Nikkhah
}

\begin{abstract}
The main goal of stemming is to standardize words by reducing a word to its origin. In this paper a new algorithm for stemming in Farsi (Persian) language is presented. This stemmer is based on removing the suffixes and prefixes, and a database is used for saving the exceptions to decrease error rate. In the proposed method the speed of stemmer and also the percentage of errors are improved. The evaluation results on the prototype document collections show significant improvement in precision and recall in comparison with other well-known methods.
\end{abstract}

Index Terms-Farsi, persian, language, stemming.

\section{INTRODUCTION}

Stemming is a fundamental step in processing textual data preceding the tasks of information retrieval, text mining, and natural language processing. The common goal of stemming is to standardize words by reducing a word to its base. In languages with very little inflection such as English and Mandarin Chinese, the stem is usually not distinct from the "normal" form of the word. However, in other languages, stems are more noticeable [1]. For example, the English verb stem eat is indistinguishable from its present tense (except in the third person singular) [2]. There is much research of the effects of stemming on searches of English document collections [3]. Stemmers such as the Lovins and Porter stemmers sometimes improve precision/recall scores [4]. However, they only stem English terms.

Farsi or Persian is an Indo-European language, spoken and written primarily in Iran, Afghanistan, and a part of Tajikistan. Like English, Farsi has affinitive morphology. In other words, suffixes and prefixes are concatenated to words to modify meaning. Farsi is read from right to left, so that prefixes are attached to the right of the root, and suffixes are attached to the left. Like English nouns, Farsi nouns are modified to signify possession, agency and plurality. However, Farsi verbs are modified more extensively than English verbs. Farsi verb forms vary according to tense, person, negation, and mood. To facilitate the information retrieval in Farsi search and display technology project [5], Kazem Taghva, Russell Beckley, and Mohammad Sadeh designed and implemented a Farsi language stemmer [3]. Its aim was to stem a word to find a more general form of it, possibly its root. For example, stemming the term interesting

Manuscript received April 8, 2011 ; revised September 22, 2011

Somayye Estahbanati is with Department of Computer Engineering. Islamic Azad University, Science and Research Branch, Ahvaz, Iran (Email: s.estahbanati@gmail.com).

Reza Javidan and Mehdi Nikkhah are with Department of Computer Engineering. Islamic Azad University, Beyza Branch, Beyza, Iran (Email: reza.javidan@gmail.com; Nikkhah@biau.ac.ir). may produce the term interest or "interes". Though a stemmer might not always give the root, that algorithm want all words that have the same stem to have the same root. On the other hand, for information retrieval, that stemmer do not always wants all words with a given root to have the same stem because some words with the same root may be topically uncorrelated e.g. preside and president.

In this paper a Farsi algorithm which is based on morphology is described (like porter algorithm in English). The algorithm is implemented and its problems were found. So these problems were solved by presenting an improved algorithm. Finally the results of first algorithm and improved algorithm were compared. The results of improved algorithm were better.

The paper is organized as follows: Section two describes related works have been done in this field .In Section three Persian morphology is described and in Section four our new Farsi stemming algorithm is proposed. Section five describes Experimental results and discussion. Finally in Section six conclusion and future works are outlined.

\section{RELATED WORKS}

Most stemming approaches are based on the target languages morphological rules (e.g., the Porter stemmer for the English language [6]) where suffix removal is also controlled by quantitative restrictions (e.g.,' ing' is removed when the resulting stem has more than three letters as in "jumping," but not in "king") or qualitative restrictions (e.g., '-ize' is removed if the resulting stem does not end with '-e' as in "seize"). Certain ad hoc spelling correction rules can also be applied to improve conflation accuracy (e.g., "running" gives "run" and not "runn"), particularly when phonetic rules are applied to facilitate easier pronunciation. Another approach consults an online dictionary to obtain better conflation results [7], while Xu \& Croft suggest a corpus-based approach that more closely reflects the language use rather than all its grammatical rules [8]. Few stemming procedures1 have been suggested for languages other than English. The proposed stemmers usually pertain to the most popular languages and some of them, like the Finnish language [9], seem to require a deeper morphological analysis to achieve good retrieval performance [10]. Algorithmic stemmer ignores word meanings and tends to make errors, usually due to over-stemming (e.g., "organization" is reduced to "organ") or to under-stemming (e.g., "create" and "creation" do not conflate to the same root).

Most of the studies so far have been involved in evaluating IR performance for the English language, while studies on the stemmer performance for less popular languages are less 
frequent. For example, Tomlinson [9] evaluated the differences between Porter's stemmer [6] strategy and lexical stemmers (based on a dictionary of the corresponding language) for various European languages. For the Finnish and the German language, lexical stemmer tends to produce statistically better results, while for seven other languages performance differences were insignificant [11].

There are two famous stemming algorithms in Farsi language:

\section{A. Kazem Taghva algorithm}

This one is like the Porter algorithm in English [6], which is based on removing the suffix and prefix. Kazem taghva, Russel Beckley and Mohammad Sadeh designed this stemmer in 2005 [3]. In this algorithm Farsi language morphology and a BNF machine whit 40 step are used to remove suffix and prefix.

\section{B. Krovetz improved algorithm in Farsi}

The second algorithm is designed by GholamReza Ghasem Sani and Reza Hesamifard [12]. This method is based on the database's information. In the other word all the stems of the language should be saved. At first the input word should be searched in the database, if it is found, the word will be returned as a stem, otherwise the suffixes and prefixes should be removed and it should be searched again in database. This method has some problems. The database needs to be update and also the speed of the stemmer is low.

\section{Persian From A Morphological Perspective}

Persian is an Indo-European language, spoken and written primarily in Iran, Afghanistan, and a part of Tajikistan. It is written from right to left in the Arabic-like alphabet. In Persian, verbs involve tense, number and person. For example1, the verb "مي خوانم"(mi-xänam: I read) is a present tense verb consisting of three morphemes. " suffix denoting first single person " خوان" (xän) is the present tense root of the verb and "مى "(mi) is a prefix that expresses continuity.

If a verb has any object pronoun, it can be attached to the end of the verb such as "ميخو انمش" (mi-xän-am-aš: I read it) in which "ش" (aš: it) is an object pronoun. Also, negative form of verbs is produced with adding "ن" (ne) to the first of them. For example, "نميخوانم" (ne-mi-xän-am - I don't read) is the negative form of the verb "ميخو انم" (mixänam - I read). There are some certain rules to make verbs in Farsi language that some of them are shown in Table I.

There are many challengeable rules for nouns that in following, one of them is described. The plural forms of nouns are formed by adding the suffixes (ها ,ان ,ات, ون , (هين). (hä) is used for all words. "ان" (än) is used for humans, animals and everything that is alive.

Also, "ات , ون , اتين" (ät ,un , in) is used for some words borrowed from Arabic and some Persian words. There are another kind of plural form in Persian that is called Mokassar which is a derivational plural form (irregulars in Persian). Some examples of plural form are shown in Table II. Also, there are some orthographic rules which show the effects of joining affixes to the word. For example, consider there are two parts of a word: A and B for joining as BA (Consider, Persian is written right to left). If the last letter of $A$ and the first letter of B are "l” (ä), one letter " $ى "(y)$ is added between them. Assume A is "آقان" (äghä - mister) and B is “"ان" (än), the joining result is “قايان" (äghä-yän: men) [13].

TABLE I: SOME RULES FOR VERBS IN PERSIAN

\begin{tabular}{|c|c|}
\hline Rule & Example \\
\hline $\begin{array}{c}\text { مى+ بن مضار ع+ شناسه مضار } \\
\text { (present person identifier + } \\
\text { present root + mi) }\end{array}$ & $\begin{array}{c}\text { مى خوانم) } \\
\text { (mi-xän-am) } \\
\text { (I read) }\end{array}$ \\
\hline $\begin{array}{l}\text { بن ماضى+ + + بود+ شناسه ماضى } \\
\text { (past person identifier + bud } \\
\text { +eh + past root) }\end{array}$ & $\begin{array}{c}\text { رفته بودم } \\
\text { (raft-e bud-am) } \\
\text { (I had gone) }\end{array}$ \\
\hline $\begin{array}{c}\text { ب }+ \text { بن مضارع root }+ \text { b) } \\
\text { (present ros }\end{array}$ & $\begin{array}{c}\text { بكذز } \\
\text { (be-gozar) } \\
\text { (Pass) }\end{array}$ \\
\hline 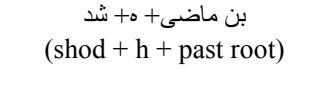 & $\begin{array}{c}\text { خو انده شد } \\
\text { (xand-e šod) } \\
\text { (it was read) }\end{array}$ \\
\hline
\end{tabular}

TABLE II: SOME KINDS OF PLURAL FORM IN PERSIAN

\begin{tabular}{|c|c|}
\hline Joining & Result noun \\
\hline $\begin{array}{c}\text { كشور + ها } \\
\text { (hä }+ \text { kešvar) } \\
\text { (hä + country) }\end{array}$ & $\begin{array}{c}\text { كثور ها } \\
\text { (kešvar-hä) } \\
\text { (countries) }\end{array}$ \\
\hline 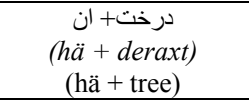 & $\begin{array}{c}\text { درختان } \\
\text { (deraxt-än) } \\
\text { (trees) }\end{array}$ \\
\hline كتب (Mokassar form) & $\begin{array}{c}\text { كتب } \\
\text { (kotob) } \\
\text { (books) }\end{array}$ \\
\hline 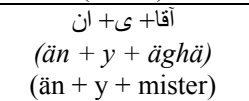 & $\begin{array}{c}\text { أقايان } \\
\text { (äghä-yän) } \\
\text { (men) }\end{array}$ \\
\hline
\end{tabular}

\section{The Proposed AlgorithM}

\section{A. The Proposed Method}

Our Farsi stemmer is based on morphology and uses multiple phases conforming to the rules of suffix stacking. Also, it enforces a lower bound on the information a stem retains. The Farsi stemmer uses stem length to define a lower bound on information content (the minimum stem length is three). This limit is crucial when a non-suffix substring of a short word is incorrectly identified as a suffix. The Farsi stemmer identifies prefixes, and it removes prefix according to defined sequences.

The first step of the stemmer algorithm is to find a terminal substring of the input word that is in a list of common Farsi morphological prefix. Then it removes the suffix of input word. If multiple suffixes match the word, the stemmer chooses the longest suffix that would leave a stem with three or more characters. Consider the Farsi word "دستشان" ("their hands"). Both the plural suffix l and the plural possessive "شان" match the end of the word. Removing "ان" leaves four letters, and removing "شان" leaves three letters. Because both leave long enough stems, the stemmer removes "شان" the longest, giving "دست" (hand).

The suffixes are grouped as verb-suffixes, plural-noun-suffixes, possessive-noun-suffixes, other-noun-suffixes (e.g. نده), and other-suffixes (e.g. تر). This grouping guides removal of prefixes from verbs and removal of multiple suffixes from a noun. If the stemmer first identifies the suffix "نز "نزفتند" in the word did not 
go") as a verb-suffix, it then identifies and removes the prefix "ن" to produce the stem "رفت" ("went"). Noun suffixes are stacked according to the pattern 1 (reading right-to-left):

$\{$ Possessive $\{$ Plural $\{$ Other $\}<$ Stem $>$

For example, the stemmer first finds the possessive noun suffix “"خمان" in the word “" "خواندهايمان" ("our singers"), then it finds the plural noun suffix "هـان" and, finally, it finds the other-noun-suffix "نده" (which signifies agency) to give the stem "خوان" ("sing"). Hence the stemmer removes up to three suffixes from nouns.

In addition, there are some unusual cases. Usually, when the stemmer finds the suffix "تان", it removes it. However, when it is preceded by "w". it ignores the suffix, because the Farsi suffix "ستان" ("location of"; pronounced "stan") is often used for countries and regions, e.g. "Kurdistan.". The stemmer does not remove "ستان" because generally, the resulting conflations (e.g. Kurd $=$ Kurdistan) are not helpful for a search engine.

Another exception is that the stemmer finds verbal suffixes "د" and "ت" but does not remove them. That the infinitives

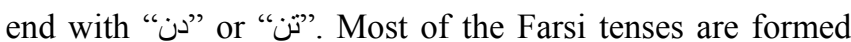
after removing the suffix "ن" but leaving characters "د" or "ت". In many cases, the stemmer looks at the letter preceding a supposed suffix. Often, this pre-suffix can be used to determine whether the match is actually a suffix and, if it is, whether it ought to be removed. In such cases, if the suffix is removed, the pre-suffix remains [14]. Our first algorithms results had some problems because of the exceptions. These exceptions should be found out to improve the algorithm.

\section{B. Implementation}

The BNF machine is used to implement the algorithm. This implementation includes a suffix stemmer and a prefix stemmer. All suffixes will be removed during the fifteen states of the suffix stemmer. Also the prefix stemmer has two states to detect and remove the prefixes. This implementation has two final steps that will be described later. To save the detected suffixes and prefixes of each word to compare the class of suffixes or prefixes whenever it needs, two arrays are used. Suffix stemmer receives the word in reverse direction. After some proportional steps one of these following final states will be observed:

State0: in this state a suffix or prefix has been detected. So it will be removed and the word will be given back to the suffixstemmer or prefixstemmer as a new word.

TABLE III: THE RESULTS OF THE ALGORITHM

\begin{tabular}{|c|c|c|c|c|}
\hline $\begin{array}{c}\text { Test } \\
\text { number }\end{array}$ & $\begin{array}{c}\text { Total } \\
\text { words }\end{array}$ & $\begin{array}{c}\text { Correct } \\
\text { results }\end{array}$ & $\begin{array}{c}\text { Incorrect } \\
\text { results }\end{array}$ & $\begin{array}{c}\text { Percentage of } \\
\text { Correct results }\end{array}$ \\
\hline 1 & 41 & 33 & 8 & 80.50 \\
\hline 2 & 89 & 76 & 13 & 85.40 \\
\hline 3 & 120 & 97 & 23 & 80.84 \\
\hline 4 & 130 & 108 & 22 & 83.07 \\
\hline 5 & 547 & 492 & 55 & 89.94 \\
\hline
\end{tabular}

Last state: the above operation is repeated until it can't detect any suffix or prefix or the word contains less than three letters. In this case the word is returned without any removal.

Prefix stemmer acts like suffix stemmer but it doesn't need to reverse the word. Before removing any suffix and prefix in each stage, the stemmer checks the suffixes and prefixes that were removed in previous steps and also it checks the type of the word. The current suffix or prefix will be removed, if its type is similar to previous removed suffixes and prefixes and it should be consistent whit the type of the word.

\section{Evaluation AND Discussion}

We select five texts with various topics on internet, and test them with our algorithm. The results are shown in Table III and Fig. 1.

As it can be seen, by increasing the quantity of tested words, the average percentage of errors is decreased. It should be noted that many of these errors are due to non-verb words that are structurally similar to verbs or because of the verbs that their stems are less than three letters. This algorithm is changed as following due to mentioned problems.

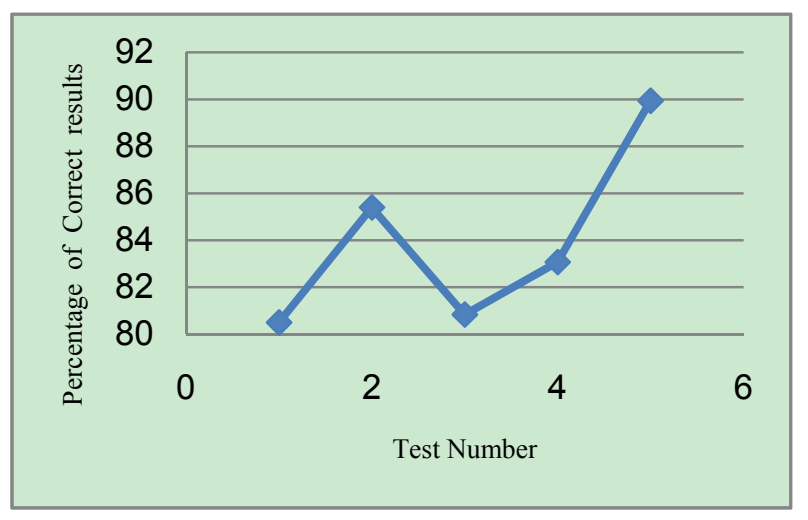

Fig. 1.The results of the algorithm

\section{A. Improvements on the Algorithm}

There are some words that are structurally similar to other words. These words should not be used by prefix stemmer and suffix stemmer. For example the first letter of non-verb word "برنامه" is "برن" which is same as the prefix of imperative verbs in Farsi. But the letter "ب" should not be removed. Or the word "نيمكت" starts with " $"$ " which is similar to negative verbs and it ends with " $ت$ " that is same as possessive pronoun. But these letters should not be removed as prefix and suffix.

Also there are some plural words in Farsi, named Mokassar which there are no certain rules to make them. Current rules couldn't be used to find these words stem.

Furthermore this algorithm has a restriction which the resulted stem should have three or more letters. But there are some words that their stem's length is less than three. For example for the verb "مىكنيم" the algorithm removes the term "مىى" as prefix. Then it detects " aي" as the longest suffix, but if the algorithm removes "يم" the remind part will have only two letters. So it removes just " $"$ " and returns "كنى" as the stem, while the correct stem is "كن".

So a data base is used to save these words stem and the algorithm is improved by considering these exceptions.

\section{B. Improvements on the Implementation}

A data base is used to improve the stemmer. In this database, non-verb words which start with a term that is similar to a verb maker prefix or words which end with a term that is similar to a suffix are saved. But if after removing 
these terms, the remained part of word had less than three letters, these words should not be saved in database.

For example the word " starts with "ميوه" which is similar to verb maker prefix "مي" in Farsi. But it's not a prefix. If the part "مي" is removed, the remained part "oو" will have only two letters. So this word should not be saved in database Or the word "نيما" starts with "ن "ن "نhich is similar to negative verb's structure. If the term " $ن$ " is removed, the remained part will have three letters. Therefore the word "نيما" should be saved in database. Also some plural words named mokassar and their singulars are saved in database. At the start of algorithm, the word should be searched in database. If it is found, its stem will be returned. Otherwise it will be used by algorithm's functions to remove suffixes and prefixes.

Furthermore, some words which their stems have less than three letters are saved in database. If after removing the suffixes or prefixes the stemmer confronts a stem with less than three letters, at first it will search the database. If the stem is found in the data base, it will be returned. But if it isn't found, the stemmer doesn't remove the suffix or prefix.

\section{Comparative Evaluation}

To evaluate these two algorithms, four different texts were selected from internet and were tested by these algorithms. The results are shown in Table IV and Fig. 2.

TABLE IV: THE RESULTS OF COMPARE

\begin{tabular}{|c|c|c|c|c|}
\hline $\begin{array}{c}\text { Test } \\
\text { number }\end{array}$ & $\begin{array}{c}\text { Percentage } \\
\text { of Correct } \\
\text { results } \\
\text { (first } \\
\text { algorithm) }\end{array}$ & $\begin{array}{c}\text { Percentage } \\
\text { of Correct } \\
\text { results } \\
\text { (Improved } \\
\text { algorithm) }\end{array}$ & $\begin{array}{c}\text { Time (first } \\
\text { algorithm) }\end{array}$ & $\begin{array}{c}\text { Time } \\
\text { (Improved } \\
\text { algorithm) }\end{array}$ \\
\hline 1 & 84.25 & 94.76 & $5 \mathrm{sec}$ & $5 \mathrm{sec}$ \\
\hline 2 & 81.65 & 97.95 & $5 \mathrm{sec}$ & $6 \mathrm{sec}$ \\
\hline 3 & 88.68 & 97.86 & $17 \mathrm{sec}$ & $18 \mathrm{sec}$ \\
\hline 4 & 88.14 & 96.78 & $25 \mathrm{sec}$ & $25 \mathrm{sec}$ \\
\hline
\end{tabular}

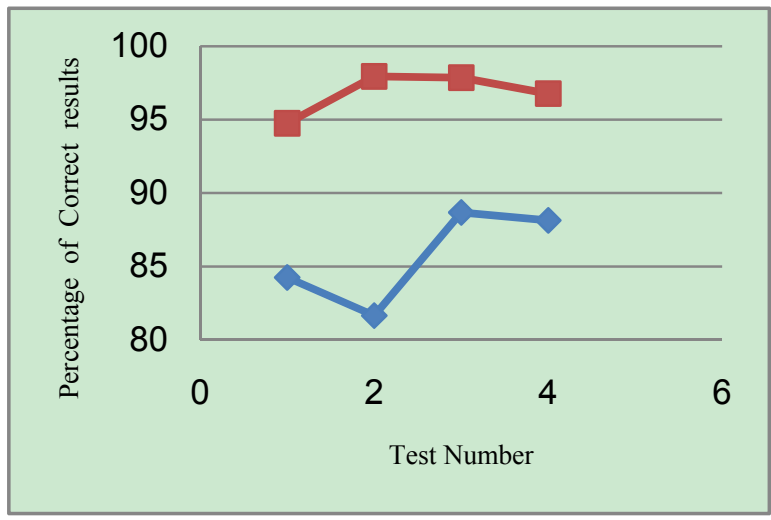

Fig. 2. Compare of two algorithms

As mentioned before, to improve our algorithm a data base is used that some exceptions are saved in it. This evaluations show that the percentage of correct results is increased while the speed of algorithm doesn't change.

\section{CONCLUSION AND REMARKS}

In this paper the stemming is described. Then the applications of stemming and different types of stemming algorithms were explained. At first an algorithm is implemented based on morphology and its problems were described. Afterward a modified algorithm was presented to improve the results. In the proposed method a database is used which contains some exceptions and based on morphology. Morphology is used to find the stem of the words. The stemmer was improved by saving the words that are similar to other words structure, and also some exceptional plural words named Mokassar and some stems that have less than three letters in a database. The number of these words is low in compare with the number of all Farsi words. But this algorithm is depended on database and in some cases the result is wrong because the stemmer can't detect the type of the words. This problem will be solved by finding out the type of the words according to the structure of the sentences.

\section{REFERENCES}

[1] Eiman Tamah Al-Shammari "Towards An Error-Free Stemming", in Proceeding of IADIS European Conference Data Mining, 2008.

[2] Kashif Riaz "Challenges in Urdu Stemming (A Progress Report)", in Proceeding of BCS IRSG Symposium: Future Directions in Information Access (FDIA 2007), 2007.

[3] Kazem Taghva, Russell Beckley, Mohammad Sadeh "A Stemming Algorithm for the Farsi Language", in Proceedings of the International Conference on Information Technology: Coding and Computing (ITCC'05) - Volume I - Volume 01 Pages: 158 - 162, 2005.

[4] David A. Hull. "Stemming algorithms case study for detailed evaluation" Technical report, Rank Xerox Research Centre, Meylen, France, June 1995.

[5] Kazem Taghva, Ron Young, Jeffrey Coombs Russell Beckley, Mohammad Sadeh and Ray Pereda "Farsi Searching and Display Technologies", in Proceeding of Symp. On Document Image Understanding Technology, pages 4146, Greenbelt, MD, April 2003.

[6] M. F. Porter. "An algorithm for sux stripping” Program, 14(3):130137, 1980.

[7] J. Savoy, "Stemming of French words based on grammatical categor,", Journal of the American Society for Information Science, vol. 44, no. 1, pp. 1-9, 1993.

[8] J. Xu and B. Croft, "Corpus-based stemming using cooccurrence of word variants," ACM-Transactions on Information Systems, vol. 16, no. 1, pp. 61-81, 1998.

[9] S. Tomlinson, "Lexical and algorithmic stemming compared for 9 European languages with Hummingbird SearchServerTM at CLEF 2003," in Comparative Evaluation of Multilingual Information Access Systems, ser. Lecture Notes in Computer Science, vol. 3237. Berlin: Springer-Verlag, pp. 286-300, 2004

[10] T. Korenius, J. Laurikkala, K. J"arvelin, and M. Juhola, "Stemming and lemmatization in the clustering of finnish text documents,", in Proceedings of the ACM-CIKM. Washington,DC: The ACM Press, pp. 625-633, 2004.

[11] Ljiljana Dolamic, Jacques Savoy "Persian Language, is Stemming Efficient?", Database and Expert Systems Application 2009. DEXA'09. 20th International Workshop on,, pages: 388 - 392 Aug. 31-Sept. 4 2009.

[12] GholamReza Ghasem Sani, Reza Hesami, "A stemming algorithm for Farsi language", in Procedding of 11 International CSI Computer Conference (CSICC'2006), 2006.

[13] Amir Azim Sharifloo, Mehrnoush Shamsfard "A Bottom up Approach to Persian Stemming" Shahid Beheshti University, Tehran, Iran.

[14] C. Peters, V. Jijkoun, T. Mandl, H. M"uller, D. Oard, A. Pẽnas, and D. Santos, Eds., "Advances in Multilingual and Multimodal Information Retrieval", Lecture Notes in Computer Scienc,. Berlin: Springer-Verlag, vol. 5152, 2008.

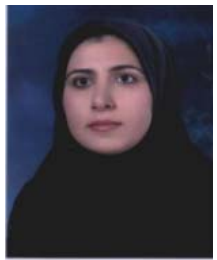

Somayyeh Estahbanati received the B.Sc degree in Computer Engineering (Software) from Islamic Azad University, Shiraz Branch. She is currently M.Sc. student in Computer Engineering (Software) in Islamic Azad University Science and Research Branch of Ahvaz, Iran. Her research interests include Artificial Intelligence, Computer programming and Database systems. 


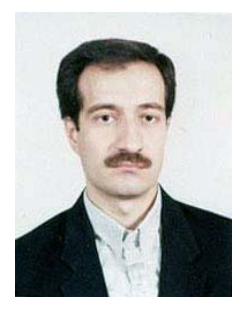

Reza Javidan received the B.Sc degree in Computer Engineering (hardware) from Isfahan University in 1993. He received M.Sc. and Ph.D. degree in Computer Science and Engineering (Artificial Intelligence) from Shiraz University in 1996 and 2007, respectively. He currently is an assistant professor and works as a lecturer in university.

He has more than 30 papers that were published in different national and international conferences and Journals. He also published a book about sonar systems. Dr. Javidan major research interests include Pattern Recognition, Image Processing, Artificial Intelligence, sonar systems and Computer Vision.

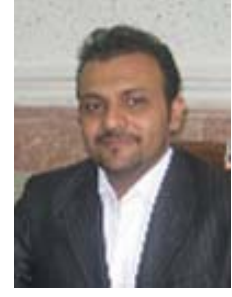

Mehdi Nikkhah received the B.Sc degree in Computer Engineering (Software) from Islamic Azad University, Shiraz Branch in 2005. He received M.Sc. degree in Computer Engineering (Software) from Islamic Azad University Science and Research Branch, Iran. He is currently member of faculty of Computer Engineering Department in Islamic Azad University, Beyza Branch His research interests include Cloud Computing, Computer programming, Grid systems, and HCI. 